\title{
Prediction of Interbeds Intercalated into Complex Heterogeneous Reservoirs at a High Water Cut Stage
}

\author{
Hou Jiagen \\ (School of Resources and Information, China University of Petroleum, Beijing 102249, China)
}

\begin{abstract}
The occurrence of interbeds in thick oil formations is one of the main reasons that cause the difference of remaining oil distribution. A quantitative method for predicting interbeds was proposed and the sedimentary origin and division criterion were demonstrated. The distribution of interbeds in different types of sedimentary sand bodies were predicted and analyzed by combining the theory of sedimentology and reservoir bed architectural-element analysis. The interbeds in a single well were recognized from high resolution well logs, and inter-well interbeds were predicted by using the methods of cyclothem correlation, physical properties truncation, and conditional simulation. Finally a 3-D model of interbed was built. Application to the Gudao Oilfield was successful.
\end{abstract}

Key words: Remaining oil, interbed, cyclothem correlation, conditional simulation

\section{Introduction}

An interbed is defined as a low permeability sublayer or an impervious stringer in a reservoir bed, such as sedimentogenic muddy intercalation, boulder clay, diagenetic calcareous layer and permeability barrier. The vertical permeability of interbeds in the rhythmic unit is much less than its horizontal permeability, which prevents the injection water from flooding below the interbed where remaining oil can accumulate, or decreases the flooding efficiency of the oil sheet above the interbeddue to the isolation by the interbed (Wang, 1987; Liu, et al., 2000; Du, et al., 2006; $\mathrm{Li}$, et al., 2007). The distribution of interbeds has a great influence on reservoir performance. The existence of interbeds reduces the net-to-gross ratio of the reservoir and the effective reservoir volume, thereby decreasing oil recovery efficiency.

In most oilfields of eastern China, the reservoir beds are fluvial deposits, delta deposits or turbidite sandstone, where the distribution of interbeds and the variation of physical properties are very complex. It is generally known that the existence of interbeds and the permeability difference influence the waterflooding performance of the reservoir bed. In recent years, it is discovered that in the middle-late development stages of waterflooding continental facies reservoirs there is considerable remaining oil above or below the low permeability sublayers interbedded in the thick oil formation. Therefore, the quantitative description of the interbed spatial distribution is the key to recovering the potential remaining oil. In the past, interbeds were only considered in research on reservoir heterogeneity; further study of the interbed distribution was rarely made and there is no matured technology for predicting inter-well interbed distribution. It is difficult to predict quantitatively the interbed distribution because of its small-scale and complicated growth in continental facies reservoir beds. The method for predicting interbed distribution at high water cut stage is presented in this paper. The spatial distribution of interbeds in different sedimentary types of reservoir beds was studied by analyzing the sedimentary origin of sand bodies. Then interbeds in a single well was recognized by using high resolution well logs, and inter-well interbeds were described by using the methods of cyclothem correlation, physical properties truncation, and conditional simulation. Finally a 3-D model of the interbeds was built.

\section{Distribution of facies-controlled interbeds}

There are different sedimentary types of sand bodies in the continental basin. The distribution of interbeds in each sand body, especially the sedimentogenic muddy intercalation was been revealed by outcrop and modern sedimentology studies (Li, 1996; Jiao and Li, 1998; Li, 2007; Quan, et al., 2007).

The main reservoir beds in the continental basin include channel and delta sand bodies. There are two types of sedimentary muddy intercalations: One is the suspended-load sediment at the land flood waning stage, which was intercalated in the upper part of the sand body and parallel to the bedding plane of the sand body; the other is the shaly draping bed between two successive lateral accretions, which makes an angle with the areal bedding plane of the sand body. The shaly draping beds, which were present in the meander bars, were always broken up by the next flooding and deposited as the boulder clay interbed in a low-sinuosity meandering river. By contraries, in a high-sinuosity 
meandering river, the shaly draping beds could be preserved well in the mid-lower part of the point bars.

The muddy intercalation in the braided river sand body refers to the silt sediment in the upper part of point bars at the channel failing stage; and the muddy intercalation between the rhythmic units in an anastomosing river sand body was well-developed and laterally continuous. The lateral width of interbeds developed in the upper part of abandoned channel sand bodies were less than the channel width.

In the delta front, the thin interbeds were likely to deposit in the lower part of the sand body only while progradation was accompanied by bottom sedimentation. In the sand sheet of the delta front, the muddy intercalation was rarely developed, or only thin calcareous interbeds were developed. In the distal bar and the estuarine bar, the interbeds were thick and distributed frequently. And in the beach bar, the interbeds were rarely developed.

\section{Recognition of interbeds in a single well}

Interbeds of several centimeters to twenty centimeters can be recognized directly on the outcrop or core sample. And interbeds more than twenty centimeters thick can be recognized in a single well from well logs, which are available in oilfields and have the high resolution of about $20 \mathrm{~cm}$.

Muddy intercalation, boulder clay interbed or calcareous intercalation has special well log response, so it is an effective way to recognize the interbeds from well logs. Take the muddy intercalation as an example, it takes on shale response characteristics on well logs: Self-potential curve returns to the highest value, the formation resistivity $\log$ decreases; both the micronormal and the microinverse are low, less than 3 $\Omega \cdot \mathrm{m}$ in general, and the difference betweem them is very small; but the SDT $\log$ and the caliper $\log$ are obviously high.

High resolution well logging tools, such as the FMI and mathematical methods, such as deconvolution, vertical resolution matching, and well logging inversion, are helpful to interbed recognition. By using Walsh function inversion and wavelet analysis, the interbeds of 0.25-0.4 m were recognized in the well Z12-J411 drilled in the Zhong 1 area, Gudao Oilfield, therefore, the thick formation Guan $4^{4}$ was divided into 2 thin layers and Guan $5^{3}$ was divided into 3 thin layers distinctly, intercalated with muddy layers

\section{Inter-well interbed prediction}

The lateral distribution of interbeds is of a different scale due to its difference in origin. Based on the thickness and scale, interbeds are divided into three classes: The first one is the continuous interbed, which extends more than the injector-producer distance; the second one is the semi-continuous interbed, which extends less than the injector-producer distance but more than half of the distance; and the last one is the discontinuous interbed, which extends less than half of the injector-producer distance.

Inter-well interbed prediction is a problem under study. Only qualitative prediction could be made based on statistical data of the frequency and density of interbeds from single well logs in the past years. The methods of quantitative prediction are presented in this paper. Guided by the distribution characteristics of facies controlled interbeds and the theory of sedimentology, the prediction of continuous interbeds was made quantitatively by cyclothem correlation; the prediction of semi-continuous interbeds was made by physical properties truncation, using the statistical width-thickness ratio as model parameter; and the prediction of discontinuous interbeds was made quantitatively by conditional simulation. Finally a 3-D model of distribution of interbeds was built.

\subsection{Cyclothem correlation}

Cyclothem correlation is an effective way of formation subdivision, and the interbeds can be recognized in the detailed reservoir description. So it is also an effective way for inter-well interbed prediction in oilfields where the well pattern is dense and the interbeds are relatively continuous.

The well log patterns are the key to recognizing sedimentary units and interbeds in cyclothem correlation, which is guided by the theory of sedimentology, and the electric properties of sedimentary units and interbeds.

Guided by the theory of sedimentary and reservoir bed architectural-element analysis, three steps were taken in cyclothem correlation. Firstly, the sedimentary origin and the depositional model should be determined; then the sand body architecture should be analyzed by following the order of the hierarchies of bounding surface; and at last the interbeds could be recognized at the boundary of the architecturalelement, and its distribution and physical properties should be studied. By using cyclothem correlation the muddy intercalation, calcareous interbed and permeability barrier were discovered in the Zao 5 group of the Kong 1 member in the Wangguantun Oilfield (Fig. 1). 


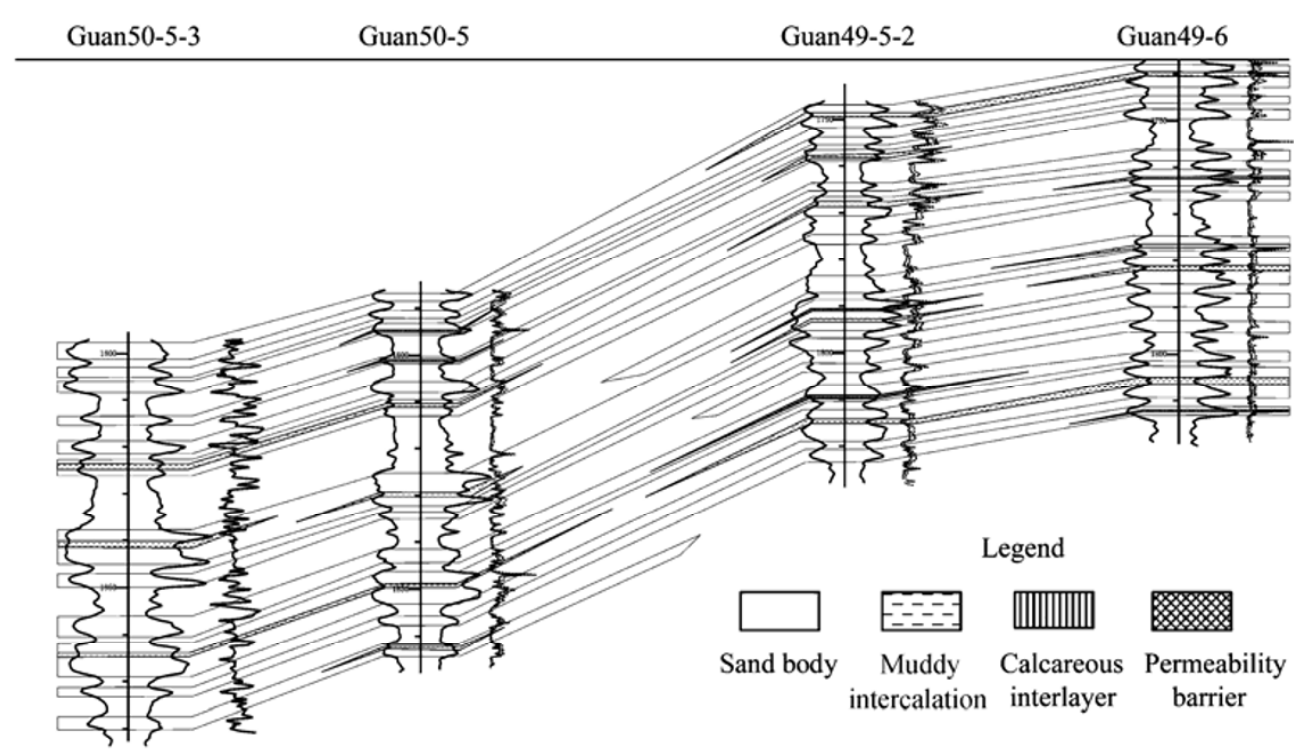

Fig. 1 Cyclothem correlation and distribution of interbeds in the Zao 5 group of Kong 1 member, Wangguantun Oilfield

\subsection{Physical properties truncation}

The method of physical properties truncation can be used to estimate the spatial distribution of interbed when the interbed is of a specific scale but the correlation is not evident. In detail, a 3-D model of reservoir parameters was built at first, and then the truncation was made for the parameter model by using the given physical properties limits of interbed. Thus the 3-D distribution model of interbed could be built.

For the Zhong 1 area in the Gudao Oilfield, the physical properties limits were summarized as follows: permeability less than $150 \times 10^{-3} \mu^{2}$, porosity less than $20 \%$. The interbed was truncated according to these criteria.

It is an effective way to predict the distribution of calcareous intercalations and permeability barriers.

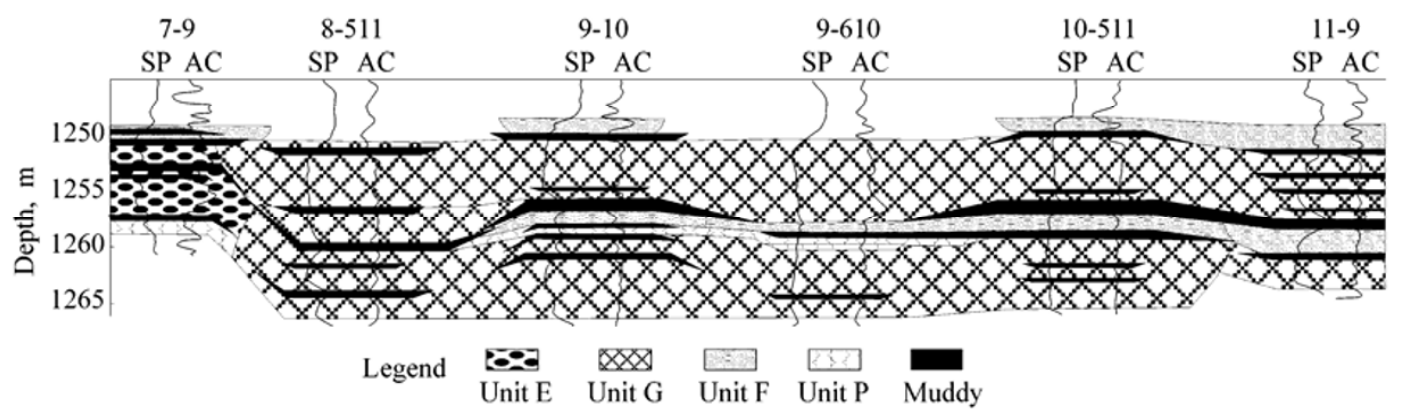

Fig. 2 Flow units and intercalation section of the Guan $5^{3}$ formation in Gudao Oilfield

\subsection{Conditional simulation}

The method of conditional simulation could be applied to identifying discontinuous interbeds, which are commonly encountered in oilfield development. The geometry and spatial distribution of this type of interbeds is complex. Based on the facies control theory, and constrained by the statistical rule of width-thickness ratio of interbeds, a final 3-D model could be built for predicting the distribution of interbeds.

\section{Application examples}

Take the Guan $5^{3}$ formation in the Zhong 1 area, Gudao Oilfield, as an example. The Guan $5^{3}$ formation, characterized by positive cyclothem, has a thickness from $8 \mathrm{~m}$ to $12 \mathrm{~m}$, with the average thickness of $8.9 \mathrm{~m}$. The intercalations, most of which are muddy intercalations, were drilled in 209 wells of the total 240 wells where the Guan $5^{3}$ formation was encountered, with the ratio of $87.1 \%$ (Table 1). The muddy 
intercalations, with a width of $0.6-2.0 \mathrm{~m}$ and a length of $100-500 \mathrm{~m}$, cover $0.02-0.2 \mathrm{~km}^{2}$ and the maximum area of intercalations can reach $0.38 \mathrm{~km}^{2}$. Due to the presence of continuous intercalation, the Guan $5^{3}$ formation is subdivided into two sedimentary units, Guan $5^{31}$ and Guan $5^{32}$. The bottom rhythmic unit Guan $5^{32}$ is $3.6-7.2 \mathrm{~m}$, with the average thickness of $5.6 \mathrm{~m}$; while the top rhythmic unit Guan $5^{31}$ is $2.5-6 \mathrm{~m}$, with the average thickness of $3.8 \mathrm{~m}$, where the reservoir bed was flooded slightly and remaining oil was accumulated.

Table 1 Statisticson the interbeds in Guan $5^{3}$ formation, Gudao Oilfield

\begin{tabular}{ccccccc}
\hline \multirow{2}{*}{ Not tapped } & & \multicolumn{4}{c}{ Tapped } \\
\cline { 5 - 7 } & & \multicolumn{2}{c}{ Thickness $<0.6 \mathrm{~m}$} & \multicolumn{2}{c}{ Thickness $>0.6 \mathrm{~m}$} \\
\cline { 1 - 5 } $\begin{array}{c}\text { Number } \\
\text { of wells }\end{array}$ & $\begin{array}{c}\text { Ratio } \\
\%\end{array}$ & & $\begin{array}{c}\text { Number } \\
\text { of wells }\end{array}$ & $\begin{array}{c}\text { Ratio } \\
\%\end{array}$ & $\begin{array}{c}\text { Number } \\
\text { of wells }\end{array}$ & $\begin{array}{c}\text { Ratio } \\
\%\end{array}$ \\
\hline 31 & 12.9 & 55 & 22.9 & 154 & 64.2 \\
\hline
\end{tabular}

According to the data from well pairs, replaced wells and other dense well pattern, the width and length of intercalation on the well point were plotted on a regular graph paper. The width-thickness ratio was calculated from this scatter diagram. The calculated width-thickness ratio of the shale intercalated in the Guan $5^{3}$ formation in Zhong 1 area, Gudao Oilfield is 301.24 (Fig. 3). Based on the pay zone and interbed data on the well point, and combined with the sedimentary characteristics, the conditional probability and the interbed distribution azimuth (azimuth $270^{\circ}$, consistent with the sediment source) were ascertained and the distribution of interbeds, which is constrained by the width-thickness ratio, was reconstructed by using the conditional simulation method (Fig. 4).

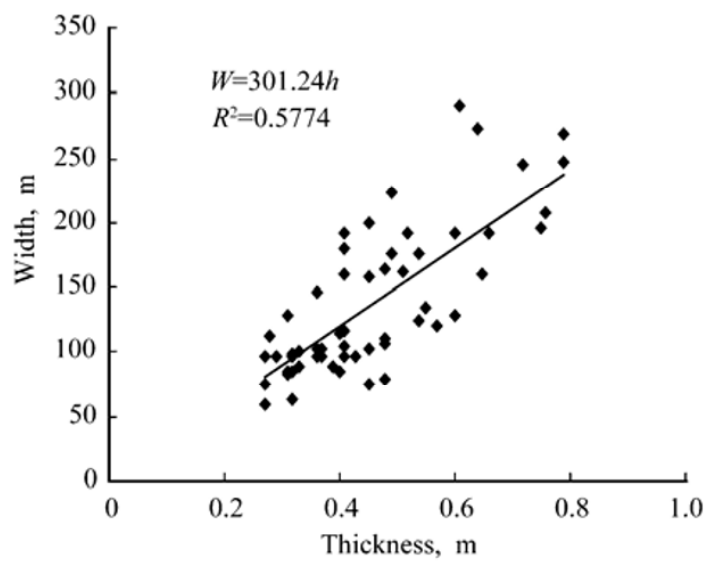

Fig. 3 Scatter diagram of the distribution of interbeds in Guan $5^{3}$ formation, Gudao Oilfield

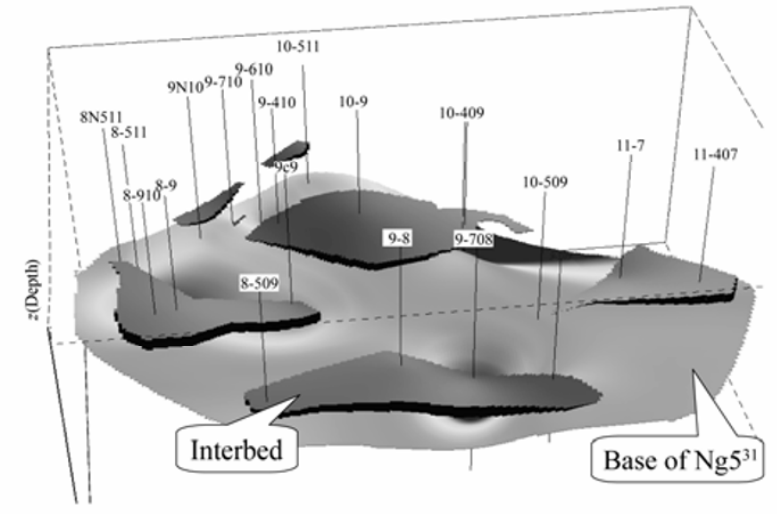

Fig. 4 A 3-D distribution model of interbeds in Guan $5^{3}$ formation, Gudao Oilfield

The spatial distribution of remaining oil could be predicted accurately by reservoir simulation based on the 3-D geological model. In order to develop the remaining oil controlled by the interbeds in the Guan $5^{31}$ formation, 15 horizontal wells were placed and 10 of the 15 wells were put into production. Contrasted with the comparable vertical wells, in the beginning of production, the daily production was 2-3 times more than that of the vertical well; water cut was $30 \%-50 \%$ less than that of the vertical well. The raising rate of water cut is $1.3 \%$ per month less than that of the vertical well; and cumulative production was three times more than that of the vertical well. In a word, remarkable effect was obtained.

\section{Conclusion}

The distribution of interbeds in different sedimentary types of sand bodies, especially the sedimentogenic muddy intercalations is complicated, but could be determined by using the theory of sedimentology and reservoir bed architectural-element analysis. Based on the interbeds recognized in a single well, the prediction of inter-well interbeds could be made by cyclothem correlation, physical properties truncation and conditional simulation.

\section{References}

Du Q. J., Chen Y. M. and Hou J. G. (2006). Control of interlayer on the distribution of remaining oil in thick reservoirs of Shengtuo Oilfield. Journal of Jianghan Petroleum Institute, 28(4), 111-114 (in Chinese)

Jiao Y. Q. and Li Z. (1998) Geologic modeling for outcrop reservoir of continental basin and the conceptual systems. Experimental Petroleum Geology, 20(4), 346-352 (in Chinese)

Li Q. (1996) Mode of deposition and intraformational anisotropic property of reservoir of clasticrock. Journal of Chengdu 
University of Technology, 23(Supplement), 22-28 (in Chinese)

Li Y., Wang D. P. and Liu J. M. (2005) Remaining oil enrichment areas in continental waterflooding reservoirs. Petroleum Exploration and Development, 32(3), 91-96 (in Chinese)

Li Y. (2007) Characterization of sedimentology in fluvial facies reservoir. Acta Sedimentologica Sinica, 25(1), 48-52 (in Chinese)

Liu J. M. Li Y. and Yan J. X. (2000) Discussion on residual oil distribution and its controlling factors in fluvial reservoir beds. Oil \& Gas Recovery Technology, 7(1), 50-53 (in Chinese)

Quan Y. W., Yao G. Q., Dong X. X., Zhou F. D., Liu B. and Huang Z. (2007) Genetic type and structure pattern of the interlayer inside thick sandbody of Baobei block in Yanqi Basin. Petroleum Geology and Engineering, 21(2), 9-12 (in Chinese)

Wang S. Q. (1987) A heterogeneous model describing the

(Continued from page 20)

Zhang M., Yin C. M., Shou J. F., et al. (2003a) Sedimentary facies of carbonate rocks of the Palaeogene and Neogene in western Qaidam Basin. Journal of Palaeogeography, 6(4), 391-400 (in Chinese)

Zhang S. W., Wang Y. M. and Li Q. (2003b) Using theory of shelf-break to find subtle oil pools. Petroleum Exploration and Development, 30(3), 5-8 (in Chinese)

Zhao C. L. (1998) Reservoir Sedimentology. Beijing: Petroleum Industry Press, 1-257 (in Chinese)

Zhao W. Z., Wang X. M., Guo Y. R., et al. (2006) Restoration and tectonic reworking of the Late Triassic basin in western Ordos Basin. Petroleum Exploration and Development, 33(1), 6-13 (in Chinese)

Zhao X. Z., Wu Y. Y., Shao W. B., et al. (2004) The prediction of potential reservoir bodies of the Palaeogene of the South-western Qaidam basin. Petroleum Exploration and Development, 31(2), 50-53 (in Chinese) heterogeneity of the production reservoir in Shuanghe Oilfield. Petroleum Exploration and Development, 14(1), 55-58 (in Chinese)

\section{About the author}

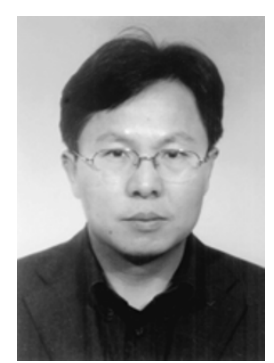

Hou Jiagen was born in 1963 and received his $\mathrm{PhD}$ degree from China University of Petroleum (Beijing) in 1997. He is a professor in the China University of Petroleum (Beijing) with his current research interests in development geology of oil and gas. E-mail: houjg63@cup.edu.cn

(Received July 13, 2006) (Edited by Sun Yanhua)

Zhu X. M. (2000) Sequence Stratigraphy. Dongying, Shandong Province: Petroleum University Publish House, 20-186 (in Chinese)

\section{About the first author}

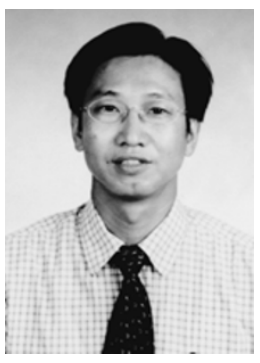

stratigraphy.
Wu Yinye, born in 1964, received his $\mathrm{PhD}$ in 1992 from China University of Petroleum (Beijing). Now he is a research professor in Research Institute of Petroleum Exploration and Development of PetroChina. He is engaged in oil and gas reservoir geology and sequence

E-mail:wyy@petrochina.com.cn

(Received July 28, 2006) (Edited by Yang Lei) 